\title{
Optimizing Machine Translation to Overcome Mechanical Engineering Vocational Education Students Difficulties in Academic Writing
}

\author{
Siti Drivoka Sulistyaningrum ${ }^{1}$, Trisya Avianka ${ }^{2}$ \\ Universitas Negeri Jakarta, Indonesia ${ }^{1,2}$ \\ Email Correspondence: drivoka@unj.ac.id
}

\begin{abstract}
Background:
Abstract

Machine translation has been proved to be a favorable style to execute. However, some research evidence difficulties indicates that its focus is on students' difficulties in academic writing, not on how to overcome them by using machine translation. As a result, this research aims to determine how machine translation might be optimized to help mechanical engineering vocational education students with academic writing difficulties.

\section{Methodology:}

The data was collected from 27 second-semester mechanical engineering vocational education students currently enrolled in an English college course at one of the Universities in Jakarta. Questionnaires online were used to obtain the data, which was analyzed and interpreted descriptively. Questionnaire 1 is used to determine whether or not the subject utilized machine translation and, if so, what type of machine translation they used most frequently. Question 2 was split into two sections. PART A was modified from Xiao \& Chen (2015), who described students' challenges with academic writing. It comprises 12 items that were delivered to 27 students via Google Form. Meanwhile, the findings of Lee (2020) have been adapted into PART B.
\end{abstract}

\section{Findings:}

The result of this study revealed that 27 students of mechanical engineering vocational education in one of the Universities in Jakarta encountered several academic writing difficulties such as grammar (construct grammatically correct sentences, the use of appropriate tenses), expressions (discourse markers, part of speech), and vocabulary (proper vocabulary choices and finding synonyms). Grammar problems are the most challenging, followed by vocabulary and phrases. The optimization of machine translation was also discovered to be the most effective way of overcoming vocabulary issues followed by grammar and expression.

\section{Conclusion:}

Academic writing issues emerge in the classroom. According to the findings, the most difficulties students encountered fell into the grammar aspect. On the other hand, the students considered that machine translation would be the most helpful in overcoming their vocabulary challenges. Although machine translation helps deal with academic writing difficulties like developing vocabulary skills, increasing knowledge of grammar rules in context, and finding more authentic expression, teachers should also guide them in writing academically.

Keywords: optimizing machine translation; academic writing difficulties; grammar; vocabulary; expressions.

\section{DOI $\quad$ : http//dx.doi.org/10.24903/sj.v6i1.714}

\begin{tabular}{l|ll}
\hline Received & $:$ & May 2021 \\
\hline Accepted & $:$ & September 2021 \\
\hline Published & $:$ & October 2021 \\
\hline
\end{tabular}

Authors retain copyright and grant the journal right of first publication with the work simultaneously licensed under a Creative Commons Attribution $\mathbf{4 . 0}$ International License that allows others to share the work with an acknowledgment of

Copyright Notice : the work's authorship and initial publication in this journal. 


\section{INTRODUCTION}

Recently, there has been wide interest in how the internet provides numerous educational benefits, particularly in a writing activity. Rabah (2015) highlighted that the optimization of learning technology as an efficient and convenient learning tool. Reviewing some previous studies confirmed that machine translation could play an effective assisting learning tool in academic writing. It is generally accepted that machine translation is one of the technologies that has been developed over the years and found its way into the field of foreign language education (Nur, Rachman, and Arbain, 2020; Arbain, 2020). In addition, reviewing from Clifford et al., (2013), 91\% of students believed the role of machine translation was useful as a dictionary and assumed that it was useful when acquiring new vocabulary. However, little information about optimizing machine translation to overcome academic writing difficulties for mechanical engineering vocational education students.

There are several reasons why this problem is essential to discover. The first reason is that various studies have shown that machine translation has advantages in learning, specifically writing. Machine translation affects the overall quality of their writing, grammar, vocabulary, and expressions Lee (2020). In line with that idea, Sukkhwan (2019) explains that many online machine translator technologies are available for internet users and language learners, such as Google Translate, Bing Translator, and Yahoo Babel fish. However, Google Translate is currently the most commonly used free machine translation available.

The second reason is the meaning of machine translation in the translation role. Herlina, Dewanti, and Lustiyantie (2019) maintain that Google Translate is an alternative tool to help students translate and improve their translation knowledge and skills. To illustrate, Google Translate is an alternative tool for translating reference books by most Applied Linguistics Doctoral Program students at Universitas Negeri Jakarta. In reality, some students said they could get the most out of self-learning if they were taught how to use Google Translate properly. It is also argued by Yamamoto, cited in (Sukkhwan, 2019) that machine translation is computer software used to translate texts from one language to another.

The third reason is in the context of English learning. Sukkhwan (2019) stated that the most common uses of Google Translate among students were word definitions, writing exercises or assignments in an English class, reading an English textbook, and translating idioms and proverbs. In line with that idea, Kim \& LaBianca (2018) indicated that English Foreign Language students, especially those for whom English is not their mother language, tend to seek help from different sources, including online sources such as Google Translate to write their paragraphs or essays. In the recent study, Alhaisoni \& Alhaysony (2017) present 
research findings on the students' attitudes of using Google Translate. A total of 92 Saudi EFL university English major students took part in the research. Almost all of the participants admitted to using Google Translate, according to the findings. The three most common purposes for using Google Translate are vocabulary, writing, and reading, with translation being the least commonly used. In brief, machine translation can be a valuable tool for language learning. However, teachers must be aware of its limitations and provide sufficient instruction to students to support student learning.

The fourth reason is in terms of writing. Writing has been an essential skill to learn in the educational field (Ariyanti, 2016). It is significant to recognize many academic goals that include writing skills such as reports, assignments, exercises, and theses (Ariyanti, 2016). Indonesia has agreed that higher education graduates have to publish the final leave project, such as an article in a journal, as the new publication reform (Mukhroji, 2020). However, problems occur under certain conditions to implement the policy. According to Fadda (2012), learning to write in academic English is problematic and challenging. In addition, Al-Badi (2015) believed it is more difficult for students who perceive English as a foreign language.

Along with that idea, he stated the reasons behind this problem; it might be caused by the differences in students' cultural backgrounds, lack of critical thinking, and low language proficiency. Furthermore, Torres \& Medriano (2020) also highlighted writing as the most difficult of the four English skills because it is embedded in the culture. Because cultures differ, differences in accepted or preferred rhetorical norms and conventions exist from one culture to another.

The fifth reason is academic writing difficulties have become a topic that researchers have noticeably considered, and different studies have been performed on this matter. Xiao \& Chen (2015) examined engineering students academic writing difficulties at the tertiary level in China. In English academic writing, the results showed that engineering students difficulties lie in three areas, i.e., content, structure, and language. It was also revealed that insufficient language use is the major problem for engineering students undertaking writing tasks. Lack of lexical variety is the highest reported challenge in language use. Recently, Noori (2020) examined undergraduate English major students' difficulties in academic writing in Afghanistan. The study's findings demonstrated that students faced a variety of problems in academic writing, including language, structure, and content. However, this research only examined a limited number of participants and at one university. Thus, this study is difficult to generalize the result of the investigation to other contexts. In another 
context, Nasser (2018) diagnosed the Iraqi EFL students writing composition difficulties revealed that the students' errors were concerned with using grammar, punctuation, spelling, and handwriting. Unfortunately, this research was limited only to style and college writing elements from paragraph to essay. Moreover, Huwari and Al-Khasawneh (2013) investigate pre-year students poor writing skills at Taibah University. This study demonstrated that grammatical weaknesses, a lack of knowledge and understanding, a lack of practice, and a lack of educational background were all factors.

Meanwhile, in Indonesian contexts, Toba, Noor, and Sanu (2019) investigate Indonesian EFL students' writing skills. They used a mixed method as the design of the study. This study revealed that some of them have concerns with content, organization, vocabulary, grammar, and mechanics in their writing. In light of the research findings, the Indonesian EFL students are suggested to increase their comparison and contrast writing ability by continuously writing and encouraging their high writing motivation. Other contexts for EFL students writing issues have emerged. Ariyanti \& Fitriana (2017) explore the difficulties EFL students face while writing essays. Qualitative research is used in this study. The results revealed that students struggle with grammatical, continuity, and coherence issues. Furthermore, minor aspects of students writing, such as paragraph organization, dictions, and vocabulary misspelling, were reported.

Along with that, many researchers have conducted prior studies regarding optimizing machine translation that are predominantly focused on English, translation, writing, and reading, not on writing difficulties. Only a few researchers seem interested in optimizing machine translation to overcome academic writing difficulties for mechanical engineering vocational education students. This gap has led the researcher to investigate this study. According to problems stated previously, two research questions are formulated: 1) What mechanical engineering vocational education students encounter academic writing difficulties? 2) How does machine translation overcome mechanical engineering vocational education students' difficulties in academic writing?

This research aims to determine how machine translation might be optimized to help mechanical engineering vocational education students with academic writing difficulties. This study is necessary to investigate because it is beneficial for other researchers interested in conducting the same area. This study is also helpful for both students and lecturers to optimize machine translation to overcome Mechanical Engineering Vocational Education students' difficulties in academic writing. 


\section{METHODOLOGY}

This present study conducts a survey research design that will be applied in academic writing classes. The survey instrument was adapted from Xiao and Chen (2015) and Lee (2020) previous studies with some adjustments. The data were gathered through two questionnaires to achieve more accurate data reflection. The first one is Questionnaire 1. It is used as a starter to know whether they were using machine translation or not when writing academically and what translation machines are used and to find out students' difficulties in academic writing. Research subjects were asked to complete the questionnaire, which includes two questions made by the researcher. Questionnaire 2 was distributed to 27 students. This questionnaire was designed to obtain the data referred to research questions 1 $\&$ 2. It was divided into two parts: PART A and PART B. The researcher modified the questionnaire items (PART A) from another relevant study by Xiao \& Chen (2015). Meanwhile, the questionnaire items (PART B) were based on the previous findings by Lee (2020) and modified by the researcher due to some adjustments. Firstly, the research subjects were asked to complete the set of the questionnaire (PART A), which includes three indicators of the questions; grammar (items 1-2), expressions (items 3-4), and vocabulary (items 5-6). Then they continued to fill questionnaire (PART B), which also includes three indicators: grammar (items 7,8), expressions (items 9, 10), vocabulary (items 11, 12). It can be concluded that the total of the questionnaire items was 12 using a 1-4 Likert scale instrument. 4-point Likert scales are included as interval level scales: $75 \leq \mathrm{x} \leq 100=$ Very Difficult/Very Good; $50 \leq \mathrm{x} \leq 75=$ Difficult/Good; $25 \leq \mathrm{x} \leq 50=$ Less Difficult/Fair; $0 \leq \mathrm{x} \leq$ $25=$ Not Difficult/Poor. The findings in this study were validated with previous similar findings by Huwari \& Al-Khasawneh's (2013); Ariyanti \& Fitriana (2017); Toba et al. (2019); and Clifford et al. (2013) study.

\section{FINDINGS}

\subsection{What are the mechanical engineering students' difficulties in academic writing?}

The questionnaire was distributed, collected, and analyzed using a percentage formula to find out academic writing difficulties encountered by mechanical engineering vocational education students. Table 1 shows the calculation's results:

Table 1. Descriptive Analysis Result on Students' Academic Writing Difficulties.

\begin{tabular}{|c|c|c|c|}
\hline Focus & Categories & Percentage & Predicate \\
\hline Students' & Grammar & $79,62 \%$ & Very Difficult \\
\hline $\begin{array}{l}\text { Difficulties in } \\
\text { Academic }\end{array}$ & Vocabulary & $72,68 \%$ & Difficult \\
\hline
\end{tabular}




\begin{tabular}{cccl}
\hline Writing & Expressions & $67,6 \%$ & Difficult \\
\hline According to table 1 , the percentage of grammar difficulties is $79,62 \%$. The
\end{tabular}
percentage is in the range of $75 \% \leq \mathrm{x} 100 \%$. It implies that the aspect lies in the predicate "Very Difficult." It also means using correct grammar is very difficult when writing academically, according to the students. The findings are verified with Huwari \& AlKhasawneh's (2013); Ariyanti \& Fitriana (2017); Toba et al. (2019); and Clifford et al. (2013) that grammar is the most challenging aspect in academic writing. The second greatest difficulty lies in vocabulary, and the percentage is $72,68 \%$. The percentage is in the range of $50 \% \leq \mathrm{x} 75 \%$. It implies that the aspect lies in the predicate "Difficult." It also shows that choosing vocabulary is difficult when writing academically. The findings are verified with Clifford et al. (2013), Lee (2020), Noori (2020), and Alhaisoni \& Alhaysony (2017) regarding vocabulary, writing, reading, grammar, and expression conclusion. In terms of expression, the percentage is $67,6 \%$. The percentage is in the range of C. It means that the aspect lies in the predicate "Difficult." It also shows that using appropriate expression is difficult in academic writing. It clarifies Lee (2020) that Machine Translation affects the overall quality of their writing; grammar, vocabulary, and expressions.

\subsection{What are the roles of machine translation in dealing with mechanical engineering students' academic writing difficulties?}

The researcher distributed questionnaire 1 to know whether in that class they are using machine translation or not. If they use it, what kind of machine translation they mostly used when doing academic writing activities. This questionnaire is aimed as a starter to find out the answers to the research questions. It is analyzed with a percentage formula. The results are presented in the table 2 :

Table 2. The Optimization of Machine Translation by Students in the Class.

\begin{tabular}{ccccc}
\hline No & Answer & Frequency & Percentage \\
\hline 1 & Yes & 27 & $100 \%$ \\
2 & & No & 0 & $0 \%$ \\
& Total & & 27 & $100 \%$ \\
\hline
\end{tabular}

From table 2, 100\% of students agree that they use machine translation to help their academic writing. It proves that students nowadays have been advanced in using technology. This also proves that machine translation is trusted to help them in language purposes, such as academic writing. It indicates that the role of dictionary is gradually replaced by machine translation, which provides efficiency to assist students' language learning. This finding confirmed with what Toba et al. (2019); Herlina et al. (2019); Ariyanti \& Fitriana (2017); and 
Clifford et al. (2013) found that the role of machine translation was helpful as a dictionary in acquiring new vocabulary.

Table 3. Kinds of Machine Translation Student's used.

\begin{tabular}{cccc}
\hline No & Answer & Frequency & Percentage \\
\hline 1 & Google Translate & 26 & $96,3 \%$ \\
2 & Bing Translator & 0 & $0 \%$ \\
3 & Yahoo Babelfish & 1 & $3,7 \%$ \\
& Total & 27 & $100 \%$ \\
\hline
\end{tabular}

According to table 3,96,3\% of the students use Google translate to assist them in academic writing activities, while 3,7\% use Yahoo Babel fish. This finding confirmed the previous study by Drugan (2013) and Sukkhwan (2019), which claimed Google Translate as the most widely used free machine translation available currently. In conclusion, 27 mechanical engineering students use machine translation when writing academically in their English subject. The vast majority of them used Google Translate as their machine translation to overcome academic writing difficulties. As far as the researcher is aware, no work confirms students can optimize machine translation in overcoming challenges in writing in academic writing, especially to overcome difficulties in grammar, vocabulary, and expressions.

\subsubsection{The optimization of machine translation to overcome students' academic writing difficulties.}

Table 4. Descriptive Analysis on The Optimization of Machine Translation to Overcome Students' Academic Writing Difficulties

\begin{tabular}{lccc}
\hline \multicolumn{1}{c}{ Variable } & Categories & Percentage & Predicate \\
\hline Optimizing machine & Vocabulary. & $81,48 \%$ & Very Good \\
translation to overcome & Grammar & $78,70 \%$ & Very Good \\
student's academic & Expressions & $72,22 \%$ & Good \\
writing difficulties & & & \\
Percentage & & $77,46 \%$ & Very Good \\
\hline
\end{tabular}

As shown in table 4, the optimization of machine translation to overcome vocabulary difficulties, the percentage is $81,48 \%$. The percentage is in the range of $75 \% \leq \mathrm{x} 100 \%$. It implies that the aspect lies in the predicate "Very Good." It also means that the optimization of machine translation is working to overcome students' academic writing difficulties in vocabulary. It is confirmed by Fadda (2012); Alhaisoni \& Alhaisony (2017); Sukkhwan (2019); and Lee (2020) that the optimization of machine translation was useful to acquire new vocabulary and to find the meanings of unfamiliar words. In terms of the optimization of machine translation to overcome grammar difficulties, the 
percentage is $78,70 \%$. The percentage is in the range of $75 \% \leq \mathrm{x} 100 \%$. It implies that the aspect lies in the predicate "Very Good." It also means that the optimization of machine translation is working to overcome students' academic writing difficulties in grammar. It clarifies by Lee (2020) that the optimization of machine translation affecting the quality of grammar. In terms of the optimization of machine translation to overcome expression difficulties, the percentage is $72,22 \%$. The percentage is in the range of $50 \%$ $\leq \mathrm{x} 75 \%$. It means that the aspect lies in the predicate "Good." It also shows that the optimization of machine translation is good enough to overcome students' academic writing difficulties in expressions. The findings are verified with Sukkhwan (2019); Kim \& LaBianca (2018); Alhaisoni \& Alhaisony (2017); and Fadda (2012) regarding the optimization of machine translation can affect the quality of expressions. In conclusion, optimizing machine translation to overcome students' academic writing difficulties is considered "Very Good," according to the 27 Mechanical Engineering Vocational Education students. The terms of very good are proved by the overall percentage of percentage calculation for all aspects and categories, which is regarded as "Very Good." The percentage is $77,46 \%$ which is in the range of $75 \% \leq x 100 \%$. This means machine translation is helpful to overcome students' academic writing difficulties, especially in terms of vocabulary.

\section{DISCUSSION}

The current research discovered that the most highly academic writing difficulty encountered by 27 Mechanical Engineering Vocational Education students is grammar. In terms of grammar difficulties, there are several potential reasons for these problematic issues. Firstly, most methods used for teaching grammar rules focus mainly on theoretical understanding rather than on any ability to implement theoretical knowledge when writing practically (Xiao \& Chen, 2015). This can contribute to students lack of understanding of complex grammar structures, as it is an element required in their academic writing. The finding is aligned with Huwari \& Al-Khasawneh's (2013); Ariyanti \& Fitriana (2017); Toba et al. (2019); and Clifford et al. (2013) study, which revealed that grammar is the most challenging part. Contradiction with this finding, Noori (2020) and Xiao \& Chen (2015) discovered that students lack vocabulary is the severest difficulty in academic writing. Consequently, to overcome the student's grammar difficulties in writing, sort of practising is needed to write skillfully and grammatically correct by optimizing machine translation tools and other grammar tools such as Grammarly, Quillbot and word processor tools. 
In this study, vocabulary comes second as the most difficulties in academic writing. The possible reason for students' difficulties with academic vocabulary varies. One key reason is the lack of experience in reading and writing English texts. Another possible explanation is lack of practice outside the classroom, and even at the school, they often use their first language (Noori, 2020). Accordingly, while writing, students have difficulty choosing the appropriate vocabulary that suits the context and finding the exact word that expresses the intended meaning. This refers to the students lack lexical knowledge. Noori (2020) and Xiao $\&$ Chen (2015) claimed that the major language difficulty in writing derives from inadequate word choices. The least difficulties encountered by the 27 students of Mechanical Engineering Vocational Education are expressions. They find it hard to use appropriate parts of speech and discourse markers. Morgan \& Bonham (1944) claimed that using part of speech could lead to the difficulty of association and word meaning. According to them, part of speech consists of nouns, pronouns, verbs, adjectives, adverbs, prepositions, articles, conjunctions, and interjections. According to Fareh et al. (2020), discourse markers are words or phrases used in speech and writing to signal relationships between discourse segments, including clauses, sentences, and even more significant portions of texts such as paragraphs.

Based on the academic writing difficulties stated above, students need a way to deal with those problems. This present study revealed the optimizing of machine translation to overcome students' academic writing difficulties. It showed that machine translation could help them the most in vocabulary followed by expressions and grammar. They think machine translation could help them in proper vocabulary choices and finding synonyms in terms of vocabulary. Similarly, Bahri \& Mahdi (2016) also revealed that machine translation, as in Google Translate, could help students solve vocabulary problems. Moreover, Burton (2003) added that students could use machine translators as a kind of multilingual dictionary that could explore language or test theories about vocabulary terms. Machine translation can also aid student writing by improving fluency in vocabulary (Xiao \& Chen, 2015). Furthermore, machine translation could better meet the needs of a language learner, while other online reference tools and dictionaries are insufficient to help learners acquire vocabulary skills (Xiao \& Chen, 2015). According to Clifford et al. (2013), the highest rates of optimizing machine translation lies in vocabulary.

In terms of grammar, they think machine translation could help them the most in construct sentences with correct grammar. According to Lee (2020), in the machine translation edition, they became mindful of possible problems when they found a different 
sentence structure from theirs. They reviewed the grammar they used to decide the correct option. In other words, it can develop students' awareness of the grammar constructed in their academic writing. This study also showed the optimizing of machine translation to overcome expression difficulties. It turned out machine translation could benefit students in finding authentic expressions. It also presented them with a different way to express the same context Lee (2020). The results also indicated that it could help them in constructing English academic writing. These findings are consistent with the consequence examined by Lee (2020). Likewise, Sukkhwan's (2019) findings, Lee (2020) also reported that machine translation, especially Google translate, is beneficial for students. They believe that Google translate could help them to improve vocabulary and finding unfamiliar meanings. It can be concluded that machine translation can help students dealing with academic writing. However, it has limitations that only could help them in terms of language use.

\section{CONCLUSION}

This research aims to figure out the optimization of machine translation to help Mechanical Engineering Vocational Education students to overcome their academic writing difficulties. The results revealed that 27 students of Mechanical Engineering Vocational Education in Universitas Negeri Jakarta encountered several academic writing difficulties such as grammar (construct grammatically correct sentences, the use of appropriate tenses), expressions (discourse markers, part of speech), and vocabulary (proper vocabulary choices and finding synonyms). The vast majority of the students considered academic writing in terms of grammar extremely difficult, vocabulary comes second, and expressions at last. The results also revealed that optimizing machine translation could assist students in facing academic writing difficulties in terms of grammar, expressions, and vocabulary. Nevertheless, a significant number of them considered machine translation as one of the alternative assisting tools to overcome vocabulary difficulties. It is also revealed that most of the students use machine translation to support their writing, and they choose Google to translate as their machine translation. This suggested that Google Translate is the most widely used free machine translation by them at the moment.

According to the findings, the current study made some recommendations. Teachers should also take part to assist them in writing academically. Firstly, teaching academic writing in English should be taken into serious consideration. Lectures should take note that language use is the greatest difficulty encountered by students in academic writing. For that reason, to 
remove their language obstacles, they should adopt and enhance their teaching strategies. Teachers are suggested to elaborately choose model compositions before the writing activities, which can afford meaningful reference for students and assist as comprehensible input. Students should be exposed to the sample articles in dealing with vocabulary choice. Lectures should guide them to notice the language features in the model compositions and encourage them to process and store the valuable language items in their memory. In this process, machine translation is taking the role. When they meet unfamiliar words, lectures should allow them to open their dictionaries or machine translation to make them easier to find the meanings to use the words in their academic writing. Lee (2020), in his study, had also shown the disadvantages of machine translation. Although machine translation helps deal with academic writing difficulties like developing vocabulary skills, increasing knowledge of grammar rules in context, and finding more authentic expression, a teacher should also assist them in writing academically. However, the main results of the current research have many implications. As seen from the findings, the students considered academic writing as a difficult task. Therefore, it needs much consideration for English academic writing could not be mastered instantly, let alone for non-native students. Students' views on the academic difficulties in their writing provide a reality of the difficulties experienced by the students and what they expect from their lecturers and the university. Furthermore, the optimization of machine translation also needs much attention to assist the students in overcoming academic writing difficulties. Further research is required in which a more significant number of participants and various academic writing difficulties should take part. A variety of research instruments should be employed to gain depth insight into the optimization of machine translation to overcome students' academic writing difficulties.

\section{REFERENCES}

Al-Badi, I. A. H. (2015). Academic writing difficulties of ESL learners. WEI International Academic Conference Proceedings, January, 63-76. http://www.westeastinstitute.com/wp-content/uploads/2015/02/Ibtisam-Ali-Hassan-AlBadi-full-Paper.pdf

Alhaisoni, E., \& Alhaysony, M. (2017). An investigation of Saudi efl University students' attitudes towards the use of google translate. International Journal of English Language Education, 5(1), 72. https://doi.org/10.5296/ijele.v5i1.10696

Arbain, A. (2020). Translating subtitles of becoming Jane Film: A pragmatic approach. Langkawi: Journal of The Association for Arabic and English, 6(1), 17-28. http://dx.doi.org/10.31332/lkw.v6i1.1766 
Ariyanti. (2016). Shaping students' writing skills: The study of fundamental aspects in mastering academic writing. Indonesian Journal of EFL and Linguistics, 1(1), 63-77. https://doi.org/10.21462/ijefll.v1i1.5

Ariyanti, A., \& Fitriana, R. (2017). EFL Students' Difficulties and Needs in Essay Writing. Advances in Social Science, Education and Humanities Research (ASSEHR). 158, 111121. https://doi.org/10.2991/ictte-17.2017.4

Bahri \& Mahdi, 2016. (2016). Google translate as a supplementary tool for learning Malay: A case study at Universiti Sains Malaysia. Advances in Language and Literary Studies, 7(3), 161-167. https://doi.org/10.7575/aiac.alls.v.7n.3p.161

Bernardini, S. (2016). Discovery learning in the language-for-translation classroom: corpora as learning aids. Cadernos de Tradução. https://doi.org/10.5007/21757968.2016v36nesp1p14

Clifford, J., Merschel, L., \& Munné, J. (2013). Surveying the landscape: what is the role of machine translation in language learning?@Tic. Revista D'Innovació Educativa, 10, 108-121. https://doi.org/10.7203/attic.10.2228

Drugan. (2013). Quality in professional translation: Assessment and improvement. United Kingdom: Bloomsbury Academic. https://doi.org/10.5040/9781472542014

Fadda, H. Al. (2012). Difficulties in academic writing: From the perspective of King Saud University postgraduate students. English Language Teaching, 5(3), 123-130. https://doi.org/10.5539/elt.v5n3p123

Fareh, S., Jarad, N., \& Yagi, S. (2020). How well can Arab EFL learners adequately use discourse markers? International Journal of Arabic-English Studies, 20(2), 85-98. https://doi.org/10.33806/ijaes2000.20.2.4

Herlina, N., Dewanti, R., \& Lustiyantie, N. (2019). Google translate as an alternative tool for assisting students in doing translation: A case study at Universitas Negeri Jakarta, Indonesia. BAHTERA: Jurnal Pendidikan Bahasa Dan Sastra, 18(1), 70-78. https://doi.org/10.21009/bahtera.181.06

Huwari, I., \& Al-Khasawneh, F. (2013). The reasons behind the weaknesses of writing in English among pre-year students' at Taibah University. Proceedings of the $3 \mathrm{rd}$ International Conference on International Studies (ICIS).

Kim, E. Y. J., \& LaBianca, A. S. (2018). Ethics in academic writing help for international students in higher education: Perceptions of faculty and students. Journal of Academic Ethics, 16(1), 39-59. https://link.springer.com/article/10.1007/s10805-017-9299-5

Lee, S. M. (2020). The impact of using machine translation on EFL students' writing. Computer Assisted Language Learning, 33(3), 157-175. https://doi.org/10.1080/09588221.2018.1553186 
Morgan, C. L., \& Bonham, D. N. (1944). Difficulty of vocabulary learning as affected by parts of speech. Journal of Educational Psychology, 35(6), 369. https://doi.org/10.1037/h0059537

Mukhroji, M. (2020). Exploring the academic writing needs to improve the academic literacy of the Indonesian efl undergraduate and masters students. International Journal of Innovation, Creativity and Change. 10(10), 252-269. http://dx.doi.org/10.24093/awej/vo19no4.31

Nasser, S. M. (2018). Iraqi efl students' difficulties in writing composition: An experimental study (University of Baghdad). International Journal of English Linguistics, 9(1), 178. https://doi.org/10.5539/ijel.v9n1p178

Nation, I. S. P. (2001). Learning vocabulary in another language. In Learning Vocabulary in Another Language. https://doi.org/10.1017/cbo9781139524759

Noori, A. (2020). An investigation of Afghan undergraduate English major students' academic writing difficulties. Journal of Foreign Language Teaching and Learning, 5(2), 99-114. https://doi.org/10.18196/ftl.5249

Nur, D., Rachman, D., \& Arbain, A. (2020). Internet usage and its impact on the academic writing performance of efl Student at Tertiary Level. In Proceedings of the 1st International Conference on Business, Law And Pedagogy, ICBLP 2019. European Alliance for Innovation (EAI). https://doi.org/10.4108/eai.16-10-2019.163226

Rabah, J. (2015). Benefits and challenges of information and communication technologies (ICT) integration in québec english schools. Turkish Online Journal of Educational Technology .... https://eric.ed.gov/?id=EJ1057526

Sukkhwan, A. (2019). Students' attitudes and behaviors towards the use of google translate. Journal of Chemical Information and Modeling, 53(9), 1689-1699.

Toba, R., Noor, W. N., \& Sanu, L. O. (2019). The current issues of Indonesian efl Students' writing skills: Ability, problem, and reason in writing comparison and contrast essay. Dinamika Ilmu, 19(1), 57-73. https://doi.org/10.21093/di.v19i1.1506

Torres, J. M., \& Medriano, R. (2020). Rhetorical organization of ilocano and Tagalog preservice teachers in their argumentative essays. Asian EFL Journal.Sian EFL Journal, 27(22), 261-286. https://www.scopus.com/inward/record.uri?eid=2-s2.085087663516\&partnerID=40\&md5=28c42edfa01e79c630c59b15eaa2b929

Xiao, G., \& Chen, X. (2015). English academic writing difficulties of engineering students at the tertiary level in China. World Transactions on Engineering and Technology Education, 13(3), 259-263. 